\title{
Differential Responses of Soybean Cultivars to Cercospora sojina Isolates, the Causal Agent of Frogeye Leaf Spot in Korea
}

\author{
Ji-Seong Kim ${ }^{1}$, Young-Su Lee ${ }^{2}$, Sung-Kee Kim², Ki Deok Kim ${ }^{3}$ and Jin-Won Kim ${ }^{1 *}$ \\ ${ }^{\prime}$ Department of Environmental Horticulture, The University of Seoul, Seoul 130-743, Korea \\ ${ }^{2}$ Environmental Agricultural Research Division, Gyonggi-do Agricultural Research and Extension Services, Hwasung 447-784, Korea \\ ${ }^{3}$ Laboratory of Plant Disease and Biocontrol, Korea University, Seoul 136-713, Korea
}

(Received on March 23, 2011; Accepted on April 17, 2011)

\begin{abstract}
During the summer of 2005, specimens of soybean cultivars (Daepung, Daewon, Hwanggeum and Taegwang) showing frogeye leaf spot (FLS) were obtained from various areas in Korea. Eight isolates identified as Cercospora sojina were inoculated on the adaxial leaf surfaces of 63 Korean soybean cultivars; the disease responses to each isolate were evaluated 14 days and 21 days after inoculation. Based on the disease responses (resistant or susceptible) of the cultivars by the isolates, a set of cultivars (Anpeong, Bogwang, Cheongdu No. 1, Cheongja No. 3, Dachae, Daemang, Jangwon, Namhae, Sowon, Taegwang) were selected and inoculated with seven isolates for further testing pathogenic variance. Interestingly, 6 out of 7 tested $C$. sojina isolates revealed differential ability in infecting different soybean cultivars. This result may indicate the possibility of new race occurrence or pathogenic variation; this also presents evidence for prevalent FLS occurrence during humid and hot weather in Korea.
\end{abstract}

Keywords : Cercospora sojina, frogeye leaf spot, soybean cultivar

Cercospora sojina is the causal agent of frogeye leaf spot (FLS) on soybeans [Glycine $\max (\mathrm{L}$.) Merr.]. The pathogen can infect leaves, stems, and seeds of the host plant. The symptoms on leaves are circular or angular, and $1-5 \mathrm{~mm}$ in diameter. The water soaked and mature symptomatic spots appear suddenly and develop into brown spots surrounded by a dark reddish brown margin (Hartman et al., 1999). Upon aging of a lesion, the center becomes grey to light brown in color and forms conidiophores and conidia. Lesions appear at time intervals and join together to form irregular lesions. When lesions cover about $30 \%$ of the total leaf area, the leaf quickly withers and falls prematurely (Hartman et al., 1999; Phillips and Boerma, 1981), resulting

\footnotetext{
*Corresponding author.

Phone) +82-2-2210-2664, FAX) +82-2-2210-2838

E-mail)jwkim@uos.ac.kr
}

in more than $35 \%$ yield loss through a reduction of seed size during hot, humid weather (Laviolette et al., 1970; Mian et al., 1998; Mwase and Kapooria, 2000; Wrather et al., 2001; Yorinori, 1981).

Epidemics and declines of FLS incidence have shown repeated cycles. New $C$. sojina races, infecting cultivars that are widely grown and resistant to established races, appear; thus, the disease is prevalent. Since a cultivar, that is resistant to a new prevalent race and a previous established race, had been developed, widely grown, the disease incidence has been declined (Athow and Probst, 1952; Athow et al., 1962; Phillips and Boerma, 1981; Ross, 1968). Many races have been reported worldwide: 12 races in the USA, 11 races in the People's Republic of China, more than 20 races in South America and a race in Japan (Hartman et al., 1999). Thus, monitoring C. sojina races and developing resistant soybean cultivars should be concerned in widely soybean-producing countries.

In Korea, although soybeans have been widely cultivated and many soybean cultivars are inbred, there has been little research concerning disease response of cultivars against $C$. sojina. Therefore, the objective of this study was to determine disease responses of ten soybean cultivars to seven $C$. sojina isolates for race identification in Korea.

FLS-diseased leaves of soybean collected from northern Gyeonggi, Gangwon, Gyeongsang, and Chungcheong provinces in July to September, 2005 were provided from Gyonggi-do Agricultural Research and Extension Services, Northern Agriculture Research Station, Yeoncheon, Korea. For fungal isolation, single spore was isolated from spots on leaves and cultured on potato dextrose agar (PDA). After incubation of these plates at $25^{\circ} \mathrm{C}$ for 10 days under a light for $12 \mathrm{hrs}$ of a day, identification was carried out based on morphological characteristics of conidia. Eight isolates from diseased leaves, that were selected based on cultivars and regions for race detection, were identified as Cercospora sojina based on the study of Shin and Kim (2001) (Table 1). Conidia are 2-8 septate, hyaline, obclavate and straight to mildly curved, with an obtuse to subobtuse apex and trun- 
Table 1. A list of eight Cercospora sojina isolates from diseased leaves of soybean cultivars by used in this study

\begin{tabular}{lllc}
\hline \hline Isolate & Province/Locality & Host cultivar & CFGR No. $^{{ }^{a}}$ \\
\hline Cs-02 & Gyeonggi/Pocheon & Daepung & 2010-113-00001 \\
Cs-10 & Gyeonggi/Yeoncheon & Daewon & $2010-113-00003$ \\
Cs-14 & Gyeongbuk/Punggi & Taegwang & 2010-113-00007 \\
Cs-16 & Gyeongnam/Daegu & Daewon & $2020-113-00009$ \\
Cs-18 & Chungbuk/Chungju & Hwanggeum & $2010-113-00011$ \\
Cs-19 & Chungbuk/Goesan & Taegwang & $2010-113-00012$ \\
Cs-20 & Chungnam/Cheonan & Taegwang & $2010-113-00013$ \\
Cs-21 & Gangwon/Jeongseon & Daewon & $2010-113-00014$ \\
\hline
\end{tabular}

${ }^{a}$ CFGR (The Center for Fungal Genetic Resources): $\mathrm{http}: / /$ genebank.riceblast.snu.ac.kr/

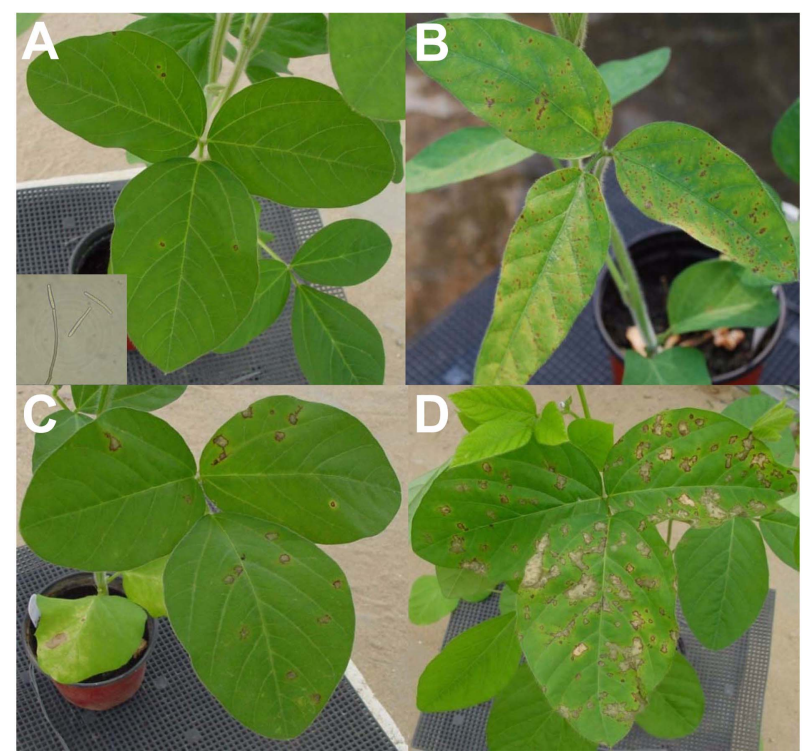

Fig. 1. Reactions of soybean trifoliate leaves of cultivars, (A) Daepung, (B) Anpeong, (C) Hwayeum and (D) Geomjeongol, inoculated with isolate CS-10 of Cercospora sojina: (A and B) resistant reactions with less than $2 \mathrm{~mm}$ diameter lesions and conidia and conidiophore (a inner box A); (C and D) susceptible reactions with more then $2-3 \mathrm{~mm}$ diameter lesion.

cate to subtruncate base. The conidia have hilum that are slightly thickened and darkened, and range $6.0-7.7 \times 38.4-$ $91.2 \mu \mathrm{m}$ in size (Fig. 1A inner box). C. sojina isolates used in this study were deposited in the Center for Fungal Genetic Resources (CFGR) at Seoul National University, Seoul, Korea.

To determine disease response of soybean cultivars to $C$. sojina, the eight isolates were inoculated to 63 cultivars (three plants per cultivar) inbred in Korea (Table 2). Singlespore isolate was cultured on V8 juice agar $[10 \%(\mathrm{v} / \mathrm{v}) \mathrm{V} 8$ juice (Cambel, U.S.A), $0.1 \%$ (w/v) $\mathrm{CaCO}_{3}, 2 \%$ (w/v) agar] at $25^{\circ} \mathrm{C}$ for 10 days under a light for $12 \mathrm{~h}$ and then added sterile water including $0.1 \%$ Tween $20(\mathrm{v} / \mathrm{v})$. The suspen-
Table 2. A list of 63 soybean cultivars used in this study

\begin{tabular}{|c|c|c|c|c|c|}
\hline No. & Cultivar & No. & Cultivar & No. & Cultivar \\
\hline 1 & Alchan & 22 & Geomgang & 43 & Jinyeul \\
\hline 2 & Anpeong & 23 & Geomjeong No. 1 & 44 & Keunol \\
\hline 3 & Baekun & 24 & Geomjeong No. 3 & 45 & Manli \\
\hline 4 & Bogwang & 25 & Geomjeong No. 4 & 46 & Meongju \\
\hline 5 & Bugwang & 26 & Geomjeongol & 47 & Namhae \\
\hline 6 & Chungdu No. 1 & 27 & Gwangan & 48 & Puleun \\
\hline 7 & Chungja & 28 & Heukchung & 49 & Pungsan \\
\hline 8 & Chungja No. 3 & 29 & Heukseolitae & 50 & Saebeol \\
\hline 9 & Chungseolitae & 30 & Hojang & 51 & Saeol \\
\hline 10 & Dachae & 31 & Hwanggeum & 52 & Samnam \\
\hline 11 & Daehwang & 32 & Hwasung & 53 & Seoklyang \\
\hline 12 & Daemang & 33 & Hwayeum & 54 & Seomoktae \\
\hline 13 & Daepung & 34 & Iksan & 55 & Sinpaldal No. 2 \\
\hline 14 & Daewon & 35 & Ilpumgeomjeong & 56 & Sobaek \\
\hline 15 & Dajang & 36 & Jangmi & 57 & Sodam \\
\hline 16 & Danbaek & 37 & Jangsu & 58 & Solok \\
\hline 17 & Daol & 38 & Jangwon & 59 & Songhak \\
\hline 18 & Dawon & 39 & Jangyeop & 60 & Sowon \\
\hline 19 & Dolemi & 40 & Jinmi & 61 & SunHeuk \\
\hline 20 & Eunha & 41 & Jinpum & 62 & Sunnok \\
\hline 21 & Galmi & 42 & Jinpum No.2 & 63 & Taegwang \\
\hline
\end{tabular}

sion was filtered through several layers of sterile cheesecloth, adjusted to $6 \times 10^{4}$ conidia/ml (Phillips and Boerma, 1981), and inoculated to the adaxial leaf surfaces of cultivars at the V3-V5 soybean development stage (Fehr et al., 1971). Inoculated seedlings were incubated at $28^{\circ} \mathrm{C}$ for $72 \mathrm{hrs}$ in a dew chamber and then transferred to the greenhouse.

Disease response was evaluated primarily on leaf spot size and secondly on the number of spots formed on the most severely affected trifoliate leaves 14 and 21 days after inoculation. The disease evaluation scale was as follows: no spot, spots $\leq 2 \mathrm{~mm}$ diameter, or $\leq 10$ spots of $2-3 \mathrm{~mm}$ diameter per trifoliate leaf were categorized as a resistant response (R); > 10 spots of $3 \mathrm{~mm}$, including spots of 2-3 $\mathrm{mm}$ diameter, was categorized as a susceptible response (S) (Fig. 1).

All tested eight isolates caused FLS on the cultivars to which they were isolated. The water soaked and mature sized spots soon appeared and developed into brown spots with dark reddish - brown margins and light brown to gray centers with conidia and conidiophores (Fig. 1C, D). Among 63 soybean cultivars, 15 certified cultivars (Korea Seed and Variety Service, 2008) (Chungja, Daewon, Eunha, Geomjeong No. 3, Hwanggeum, Heukchung, Jangmi, Jangyeop, Jinpum, Jinpum No. 2, Saeol, Sodam, Solok, Songhak, and Taegwang) and 15 other soybean cultivars (Alchan, Daehwang, Galmi, Geomjeong No. 1, Geomjeongol, Iksan, 
Table 3. Differential reactions of soybean cultivars to seven isolates of Cercospora sojina for race identification 14 days and 21 days after inoculation

\begin{tabular}{lccccccc}
\hline \hline \multirow{2}{*}{ Cultivar } & \multicolumn{7}{c}{ Isolate } \\
\cline { 2 - 7 } & Cs-02 & Cs-10 & Cs-14 & Cs-16 & Cs-19 & Cs-20 & Cs-21 \\
\hline Anpeong & $\mathrm{R}^{\mathrm{a}}$ & $\mathrm{R}$ & $\mathrm{R}$ & $\mathrm{R}$ & $\mathrm{R}$ & $\mathrm{R}$ & $\mathrm{R}$ \\
Bogwang & $\mathrm{R}$ & $\mathrm{R}$ & $\mathrm{R}$ & $\mathrm{R}$ & $\mathrm{R}$ & $\mathrm{R}$ & $\mathrm{R}$ \\
Cheongdu & $\mathrm{S}$ & $\mathrm{S}$ & $\mathrm{S}$ & $\mathrm{R}$ & $\mathrm{S}$ & $\mathrm{R}$ & $\mathrm{R}$ \\
No. 1 & & & & & & & \\
Cheongja & $\mathrm{R}$ & $\mathrm{S}$ & $\mathrm{S}$ & $\mathrm{R}$ & $\mathrm{S}$ & $\mathrm{R}$ & $\mathrm{R}$ \\
No. 3 & & & & & & & \\
Dachae & $\mathrm{R}$ & $\mathrm{S}$ & $\mathrm{S}$ & $\mathrm{S}$ & $\mathrm{R}$ & $\mathrm{S}$ & $\mathrm{R}$ \\
Daemang & $\mathrm{S}$ & $\mathrm{S}$ & $\mathrm{S}$ & $\mathrm{R}$ & $\mathrm{S}$ & $\mathrm{R}$ & $\mathrm{S}$ \\
Jangwon & $\mathrm{R}$ & $\mathrm{R}$ & $\mathrm{R}$ & $\mathrm{S}$ & $\mathrm{R}$ & $\mathrm{S}$ & $\mathrm{R}$ \\
Namhae & $\mathrm{S}$ & $\mathrm{S}$ & $\mathrm{S}$ & $\mathrm{R}$ & $\mathrm{R}$ & $\mathrm{S}$ & $\mathrm{R}$ \\
Sowon & $\mathrm{S}$ & $\mathrm{R}$ & $\mathrm{R}$ & $\mathrm{S}$ & $-{ }^{\mathrm{b}}$ & $\mathrm{S}$ & $\mathrm{R}$ \\
Taegwang & $\mathrm{S}$ & $\mathrm{S}$ & $\mathrm{S}$ & $\mathrm{S}$ & $\mathrm{S}$ & $\mathrm{S}$ & $\mathrm{S}$ \\
\hline
\end{tabular}

${ }^{a}$ reaction types: $\mathrm{R}=$ resistant and $\mathrm{S}=$ susceptible.

${ }^{\mathrm{b}}$ not tested.

Jangsu, Jinyeul, Keunol, Manli, Puleun, Saebeol, Seomoktae, Sobaek and Sunnok) showed a "susceptible" response to all eight isolates.

Seven isolates, except for isolate CS-18 that failed to sporulate in mass, were inoculated to selected 10 soybean cultivars, which produced distinct disease responses. The experiment was performed more than twice with ten replicates per trial. As a result of inoculation, six of seven isolates of C. sojina represent distinguishing ability to infect different cultivars (Table 3); Cs-10 and Cs-14 isolates induced identical disease response from ten cultivars. Both cultivars Anpeong and Bogwang were resistant to all seven isolates, while cultivar Bogwang did not form any spots, cultivar Anpeong formed numerous but tiny spots of $\leq 2$ $\mathrm{mm}$ surrounded by yellowish halo (Fig. 1B).

Phillips and Boerma (1981) and Shirai et al. (1994) rated disease responses 14 days after inoculation. Yorinori (1981) evaluated disease response in greenhouse experiments at 5 to 7 days after appearance of the first visible lesion and reported that the first lesion appeared 8 to 18 days after inoculation. In this study, the first lesion appeared 8 to 17 days after inoculation, thus a disease rating 18 days from the date of inoculation was essential. In artificial inoculation, since only inoculated leaves form lesions and fall prematurely (Phillips and Boerma, 1981; Yorinori, 1981), a disease rating 5 to 7 days from the date of initial lesion appearance is also essential. Accordingly, we also performed disease ratings both 14 days and 21 days after inoculation.

In this study, evaluation scale ratings of no spot, $\leq 2 \mathrm{~mm}$ diameter spots, or $\leq 10$ spots of $2-3 \mathrm{~mm}$ diameter were regarded as a resistant response (R); $\geq 10$ spots of $3 \mathrm{~mm}$, including 2-3 $\mathrm{mm}$ diameter, were regarded as a susceptible response (S) (Table 3). These criteria correspond exactly to those of Yorinori (1981). Many researchers use 'intermediate' as rating category, but this rating category might be inappropriate due to the differences in repeated experiments or growth conditions (Ross, 1978; Yorinori, 1981). Thus we used the evaluation scale (R or S) as mentioned above.

Cultivar Anpeong formed numerous but tiny spots of $\leq 2$ $\mathrm{mm}$ diameter, surrounded by a yellowish halo and was regarded as "resistant". Shirai et al. (1994) also regarded cultivars which form numerous but tiny spots as resistant. This numerous but tiny spots also appeared on cultivar Daemang inoculated with isolates Cs-16 and Cs-20. Although lesions surrounded by yellowish halos were also observed on lesions of susceptible cultivars, more distinct halos were observed on numerous but tiny lesions. Yellowish halos appeared to surround lesions by some bacteria and they are due to bacterial toxin (Tamura et al., 2002). Yellowish halos were also observed around lesions by toxin produced fungus, Colletotrichum dematium and C. caricis (Blaney et al., 1988; Yoshida et al., 2000). Benedict and Fucikovski (1966) suggested that of FLS lesions result from one or more substances produced by $C$. sojina. Cercosporin is well known as a toxin produced by genus Cercospora, but $C$. sojina does not produce cercosporin (Stephen et al., 2001). Thus, yellowish halo surrounding the lesions are considered to result from other toxins produced by $C$. sojina.

Most certified soybean cultivars of Korea supplied from 2005 to 2009, including the major certified soybean cultivars, cultivars Daewon, Hwanggeum and Taegwang were susceptible to eight $C$. sojina isolates tested in this study. Therefore, this result may indicate the possibility of new race occurrence or pathogenic variation and prevalent FLS occurrence during humid and hot weather in Korea. To verify the existence of $C$. sojina race, more tests including previously reported race will to be needed.

\section{Acknowledgment}

This work was supported by the University of Seoul Research Fund in 2008.

\section{References}

Athow, K. L. and Probst, A. H. 1952. The inheritance of resistance frogeye leaf spot of soybean. Phytopathology 42:660662.

Athow, K. L., Probst, A. H., Kurtzman, C. P. and Laviolette, F. A. 1962. A newly identified physiological race of Cercospora sojina on soybean. Phytopathology 52:712-714. 
Benedict, W. G. and Fucikovsky, L. A. 1966. Cercospora sojina lesion on soybeans. Can. J. Plant Sci. 46:567-568.

Blaney, C. L., Gerald Van Dyke, C. and Grand, L. F. 1988. Cercospora caricis from Cyperus esculentus (Yellow Nutsedge): Morphology and cercosporin production. Mycologia 80:418421.

Fehr, W. R., Caviness, C. E., Burwood, D. T. and Pennington, J. S. 1971. Stage of development descriptions for soybean. Glycine $\max ($ L.) Merr. Crop Sci. 11:929-931.

Hartman, G. L., Sinclair, J. B. and Rupe, J. C. 1999. Frogeye leaf spot. In: Compendium of Soybean Diseases, 4th ed., pp. 20-21. Am. Phytopathol. Soc., St. Paul, MN.

Korea Seed and Variety Service. 2008. Supply of soybean certificated seed http://order.seed.go.kr/SDCT/index.jsp

Laviolette, F. A., Athow, K. L., Probest, A. H., Wilcox, J. R. and Abney, T. S. 1970. Effect of bacterial pustule and frogeye leaf spot on yield of Clark soybean. Crop Sci. 10:418-419.

Mian, M. A. R., Boerma, H. R., Phillips, D. V., Kenty, M. M., Shannon, G., Shipe, E. R., Soffes Blount, A. R. and Weaver, D. B. 1998. Performance of frogeye leaf spot -resistant and -susceptible near-isolines of soybean. Plant Dis. 82:1017-1021.

Mwase, W. F. and Kapooria, R. G. 2000. Incidence and severity of frogeye leaf spot and associated yield losses in soybeans in agroecological zone II of Zambia. Mycopathologia 149:7378.

Phillips, D. V. and Boerma, H. R. 1981. Cercospora sojina race 5: A threat to soybeans in the southeastern United States. Phytopathology 71:334-336.

Ross, J. P. 1968. Additional physiological races of Cercospora sojina on soybeans in North Carolina. Phytopathology 58: 708-709.

Shin, H. D. and Kim, J. D. 2001. Cercospora and allied genera from Korea. National Institute of Agricultural Science and Technology. 302 pp.

Shirai, K., Horita, H., Tanaka, F. and Tanii, A. 1994. A New Race of Cercospora sojina in Hokkaido. Ann. Phytopath. Soc. Japan 60:694-697.

Stephen, B., Goodwin, S. B., Dunkle, L. D. and Zismann, V. L. 2001. Phylogenetic analysis of Cercospora and Mycosphaerella based on the internal transcribed spacer region of ribosomal DNA. Phytopathology 91:648-658.

Tamura, K., Imamura, M., Yoneyama, K., Kohno, Y., Takikawa, Y., Yamaguchi, I. and Takahashi, H. 2002. Role of phaseolotoxin production by Pseudomonas syringae pv. actinidiae in the formation of halo lesions of kiwifruit canker disease. Physiol. Mol. Plant Pathol. 60:207-214.

Wrather, J. A., Anderson, T. R., Arsyad, D. M., Tan, Y., Ploper, L. D., Porta-Puglia, A., Ram, H. H. and Yorinori, J. T. 2001. Soybean disease loss estimates for the top ten soybean-producing countries in 1998. Can. J. Plant Pathol. 23:115-121.

Yorinori, J. T. 1981. Cercospora sojina: pathogenicity, new races and transmission in soybeans. Ph. D. thesis, Department of Plant Pathology, University of Illinois at Urbana-champaign, Urbana. 174pp.

Yoshida, S., Hiradate, S., Fujii, Y. and Shirata, A. 2000. Colletotrichum dematium produces phytotoxins in anthracnose lesions of mulberry leaves. Phytopathology 90:285-291. 